\title{
Extensive tissue-regenerative capacity of neonatal human keratinocyte stem cells and their progeny
}

\author{
Amy Li, Normand Pouliot, Richard Redvers, and Pritinder Kaur \\ Epithelial Stem Cell Biology Laboratory, Peter MacCallum Cancer Centre, St. Andrew's Place, Melbourne, Victoria, Australia
}

Given our recent discovery that it is possible to separate human epidermal stem cells of the skin from their more committed progeny (i.e., transit-amplifying cells and early differentiating cells) using FACS techniques, we sought to determine the comparative tissue regeneration ability of these keratinocyte progenitors. We demonstrate that the ability to regenerate a fully stratified epidermis with appropriate spatial and temporal expression of differentiation markers in a short-term in vitro organotypic culture system is an intrinsic characteristic of both epidermal stem and transit-amplifying cells, although the stem cell fraction is most capable of achieving homeostasis. Early differentiating keratinocytes exhibited limited short-term tissue regeneration under specific experimental conditions in this assay, although significant improvement was obtained by manipulating microenvironmental factors, that is, coculture with minimally passaged dermal cells or exogenous supply of the ECM protein laminin-10/11. Importantly, transplantation of all classes of keratinocyte progenitors into an in vivo setting demonstrated that tissue regeneration can be elicited from stem, transit-amplifying, and early differentiating keratinocytes for up to 10 weeks. These data illustrate that significant proliferative and tissue-regenerative capacity resides not only in keratinocyte stem cells as expected, but also in their more committed progeny, including early differentiating cells.

J. Clin. Invest. 113:390-400 (2004). doi:10.1172/JCI200419140.

\section{Introduction}

The epidermis forms the outer protective layers of the skin and is a rapidly renewing tissue undergoing constant regeneration. This extensive capacity for cell renewal in vivo has also been observed in vitro, particularly when epidermal cells are cocultured with feeder cells (1). Furthermore, dissociated specimens of skin and mucosa will regenerate an epithelium when transplanted onto suitable in vivo sites on histocompatible hosts (2-4). In humans, autologous grafts of cultured human epidermal sheets are capable of rescuing patients with full-thickness burns covering up to $98 \%$ of their body surface and can be maintained for over a decade $(5,6)$. While these studies demonstrate the immense regenerative capacity of keratinocytes, it is not clear which particular population of cells is responsible, given that much of this work uses mass cultures of epidermis. Extensive cell kinetic analyses of epithelial turnover in murine tissues suggests that, in vivo,

Received for publication June 6, 2003, and accepted in revised form November 19, 2003.

Address correspondence to: Pritinder Kaur, Epithelial Stem Cell Biology Laboratory, Peter MacCallum Cancer Centre,

St. Andrew's Place, Melbourne, Victoria 3002, Australia.

Phone: 61-3-9656-3714; Fax: 61-3-9656-3738;

E-mail: pritinder.kaur@petermac.org.

Amy Li and Normand Pouliot made substantial contributions to this work.

Conflict of interest: The authors have declared that no conflict of interest exists.

Nonstandard abbreviations used: transit amplifying (TA); keratinocyte stem cell (KSC); postmitotic differentiating (PMD); laminin-10/11 (LN-10/11); dermal equivalent (DE); passage (p); unfractionated (UF). sustained cell renewal can be attributed to long-lived epidermal stem cells, given the finite life span of the majority of proliferative basal epidermal cells (transitamplifying cells [TA cells]) and their rapid loss to terminal differentiation within a period of weeks (7-13). It is well accepted that the extensive growth capacity exhibited by epidermal cells in culture can most likely be attributed to the activity of stem cells, given that the transplanted cells give rise to self-renewing epithelium over extended periods of time $(14,15)$. The underlying assumption is that epithelial tissue regeneration is the hallmark of a stem cell and not its committed progeny in both short-term tissue reconstitution (16) and longterm tissue regeneration assays $(14,15)$. Clearly, the development of methods to identify and assay epidermal stem cells and their progeny prospectively is essential to test these assumptions.

Initial studies to define cell-surface markers for epidermal stem cells led to the conclusion that basal keratinocytes expressing high levels of $\beta_{1}$ integrin were enriched for cells with high colony-forming efficiency in vitro and the ability to reform epithelial tissue in vivo $(16,17)$. Subsequent work from a number of laboratories has demonstrated that, while the majority of basal epidermal cells express high levels of integrin (16, 18-20), only a minor subset of these represent stem cells as defined by their ability to retain a ${ }^{3} \mathrm{H}-\mathrm{Tdr}$ label for 8 weeks or more (20-22), a well-accepted characteristic of quiescent stem cells in vivo $(8,11,13,23-25)$. We have further shown that label-retaining cells can be distinguished from other integrin bright, rapidly cycling TA cells by their characteristic low levels of CD71 (transferrin receptor) expression $(18,22)$. Thus, 
keratinocyte stem cells (KSCs) can be isolated prospectively from neonatal human and adult murine skin by FACS analysis based on their $\alpha_{6}{ }^{\text {bri CD }} 71^{\text {dim }}$ phenotype, and they represent approximately $4-7 \%$ of total basal cells. Other stem cell criteria exhibited by cells of the phenotype $\alpha_{6}{ }^{\text {bri }}$ CD71 dim include small cell size (approximately $9 \mu \mathrm{m}$ ), blastlike morphology with a high nuclear-to-cytoplasmic ratio, quiescence as shown by cell-cycle analysis, and the greatest long-term proliferative capacity to regenerate keratinocytes in vitro (18, 22). Taken together, these data demonstrate that the $\alpha_{6}{ }^{\text {bri }} \mathrm{CD} 71^{\mathrm{dim}}$ fraction is enriched for stem cells and are thought to represent the most well-characterized epidermal stem cell population described to date $(26,27)$. Furthermore, the cell-surface phenotype of the progeny of KSCs, that is, TA cells and early differentiating cells, previously termed the postmitotic differentiating (PMD) fraction, which is based on nomenclature derived from morphological studies of murine epidermis $(28,29)$, was defined as $\alpha_{6}{ }^{\text {bri }} C D 71^{\text {bri }}$ and $\alpha_{6}{ }^{\text {dim }}$, respectively. The $\alpha_{6}{ }^{\text {bri }} \mathrm{CD} 71^{\text {bri }}$ TA population was characterized by its enrichment for actively cycling cells identified as pulse-labeled cells in murine skin, exhibiting lower long-term keratinocyte cell regeneration in vitro compared with the KSCs. The $\alpha_{6}{ }^{\mathrm{dim}}$ cells could be distinguished by their relatively poor long-term proliferative output and were inferred to be in the early stages of differentiation based on their expression of keratin 10 and involucrin (18).

In this study we sought to assay the epidermal regenerative potential of the $\alpha_{6}{ }^{\text {bri }} \mathrm{CD} 71^{\mathrm{dim}}$ cells compared with their more committed progeny, given that an important characteristic of stem cells is their ability to regenerate their tissue of origin (30). We used a wellcharacterized organotypic culture model system in which keratinocytes are cocultured with fibroblasts, the latter providing dermal factors essential for epidermal proliferation, differentiation, and morphogenesis (31-33). This is an ideal model for determining the short-term epidermal regenerative potential of various fractions of basal keratinocytes since disaggregated populations of human keratinocytes can be assayed for their ability to regenerate a multilayered epidermis that closely resembles the normal tissue both morphologically and biochemically. We report here that, as expected, KSCs $\left(\alpha_{6}{ }^{\text {bri }}\right.$ CD71 $\left.{ }^{\mathrm{dim}}\right)$ had the greatest intrinsic capacity to regenerate a normal, multilayered epithelium. To our surprise, however, we could elicit this property from the progeny of stem cells, that is TA cells $\left(\alpha_{6}{ }^{\text {bri }} \mathrm{CD} 71^{\text {bri }}\right)$ and even the differentiating, keratin 10 , and involucrin-positive $\alpha_{6}{ }^{\mathrm{dim}}$ cells, under the appropriate microenvironmental influences specifically cocultured with minimally passaged dermal cells and the ECM proteins laminin-10/11 (LN-10/11). Given that the organotypic culture model is short-lived and that tissue regeneration determined over 2 weeks could reasonably be considered a wound-healing response, we assayed longer-term tissue regeneration from fractionated keratinocytes following in vivo transplantation. Our results indicate that stem, TA, and early differentiating keratinocytes are all capable of prolonged tissue regeneration in vivo, revealing a greater capacity for cell renewal than predicted of the more committed progeny of stem cells.

\section{Methods}

Isolation of primary basal epidermal cells and dermal fibroblasts. Primary basal keratinocytes were isolated from neonatal foreskins as described (18). The dermal foreskin tissue was digested in $4 \mathrm{mg} / \mathrm{ml}$ dispase and 3 $\mathrm{mg} / \mathrm{ml}$ of collagenase (Worthington Biochemical Corp., Lakewood, New Jersey, USA) in PBS at $37^{\circ} \mathrm{C}$ for 1.5 hours, and the resultant cell suspension was filtered through a $70-\mu \mathrm{m}$ cell strainer (Becton Dickinson Co., Franklin Lakes, New Jersey, USA). Dermal cells were cultured in DMEM supplemented with 10\% FCS, L-glutamine (2 mM; Multicel; Trace Biosciences Pty. Ltd., Castle Hill, New South Wales, Australia), penicillin $(1.2 \mu \mathrm{g} / \mathrm{ml})$, gentamycin $(16 \mu \mathrm{g} / \mathrm{ml})$, sodium pyruvate (1 mM; Life Technologies Inc., Gaithersburg, Maryland, USA) (DMEM-10).

$A b$ 's. For FACS analysis, $10 \mu \mathrm{g} / \mathrm{ml}$ anti- $\alpha_{6}$ integrin $\mathrm{mAb} 4 \mathrm{~F} 10$ ( $\mathrm{IgG}_{2 \mathrm{~b}}$; Serotec Ltd., Oxford, United Kingdom) was used, and mAb $10 \mathrm{G} 7\left(\operatorname{IgG}_{2 \mathrm{a}}\right)$ against the human transferrin receptor CD71 (34) was used as hybridoma supernatant. Isotype-matched negative controls, mAb's 1A6.11 ( $\left.\operatorname{IgG}_{2 \mathrm{~b}}\right)$ and 1D4.5 ( $\left.\mathrm{IgG}_{2 \mathrm{a}}\right)$, were used as described (18). Secondary Ab's, anti-rat $\operatorname{IgG}_{2 b^{-}}$ FITC and $\operatorname{IgG}_{2 \mathrm{a}} \mathrm{PE}$ (Caltag Laboratories Inc., Burlingame, California, USA), were used to detect 4F10 and 10G7 binding, respectively.

For immunohistochemistry, mAb's against K14 (LL001, IgG 2 ; 1 :1,000), K10 (LHP2, IgG 1 ;:10), K15 (LHK15, IgG 2 ; 1 1:10), and K16 (LL025, IgG 2 ; $1: 10$ ) were supplied by I. Leigh (Royal London Hospital, London, United Kingdom) as hybridoma supernatants. P5D2, the $\mathrm{mAb}$ to the $\beta_{1}$ integrin $\left(\mathrm{IgG}_{1}\right.$; a gift from $\mathrm{W}$. Carter, Fred Hutchinson Cancer Research Center, Seattle, Washington, USA) was used as neat hybridoma supernatant, and mAb 4F10 ( $\alpha_{6}$ integrin) was used at 10 $\mu \mathrm{g} / \mathrm{ml}$. Rabbit polyclonal Ab's to involucrin and filaggrin were a kind gift from R. Rice (University of California, Davis, California, USA) and B. Dale (University of Washington, Seattle, Washington, USA), respectively; both were used at 1:1,000. The mAb P1E1 was used to detect $\mathrm{LN}-5 \alpha 3$ chain $\left(\mathrm{IgG}_{1}\right.$; hybridoma supernatant provided by W. Carter) and mAb 4C7 to LN-10/11 $\alpha 5$ chain (mouse $\operatorname{IgG}_{2 a}, 1: 200$; Chemicon International Inc., Temecula, California, USA). Isotype control mAb's 1A6.11 $\left(\operatorname{IgG}_{2 \mathrm{~b}}\right), 1 \mathrm{D} 4.5\left(\operatorname{IgG}_{2 \mathrm{a}}\right)$, and $1 \mathrm{~B} 5\left(\operatorname{IgG}_{1}\right)$ were used as neat hybridoma supernatants. Rabbit Ig fraction (2 $\mu \mathrm{g} / \mathrm{ml}$; DAKO Corp., Carpinteria, California, USA) provided a negative control for polyclonal Ab's.

Immunofluorescence staining of primary keratinocytes and FACS. Basal keratinocytes were processed for $\alpha_{6}$-FITC and CD71-PE double staining along with appropriate negative controls and single-color positive controls to establish the compensation setting for FACS analysis as described previously $(18,19)$. Cells were resuspended in 
culture medium at $2 \times 10^{6}$ to $3 \times 10^{6} / \mathrm{ml}$ and sorted using the Becton Dickinson Immunocytometry Systems (San Jose, California, USA) FACStarplus. A small aliquot from each of the collected fractions was reanalyzed routinely for sort purity.

Organotypic cultures. Organotypic cultures were constructed using a previously established transwell system consisting of a collagen type I lattice populated with fibroblasts known as dermal equivalents (DEs), onto which the keratinocytes were seeded (35). DEs were prepared by polymerizing $1 \mathrm{ml}$ acellular bovine collagen type 1 , followed by $3 \mathrm{ml}$ of collagen matrix containing $2.5 \times 10^{4}$ passage 1 ( $\mathrm{p} 1$ ) or $\mathrm{p} 7$ dermal fibroblasts per well on the insert. DEs were cultured submerged in DMEM-10 for 6 days prior to the addition of basal keratinocytes to allow gel contraction. Subsequently, $4.5 \times 10^{4}$ or $1 \times 10^{4}$ unfractionated (UF) cells, PMD cells, TA cells, or KSCs were seeded per collagen gel. Triplicate wells were set up for each fraction of keratinocytes. In experiments where $\mathrm{LN}-10 / 11$ was used, the DEs were coated first with $50 \mu \mathrm{l}$ of LN-10/11 (10 $\mu \mathrm{g} / \mathrm{ml}$; Life Technologies Inc.) for 30 minutes at $37^{\circ} \mathrm{C}$ and the keratinocytes resuspended in $10 \mu \mathrm{g} / \mathrm{ml}$ of LN$10 / 11$ prior to seeding onto the DEs.

The organotypic cultures were maintained for 4 days in a 3:1 mix of DMEM and Ham's F12 with $0.3 \%$ FCS, 4 $\mathrm{mM}$ L-glutamine (Multicel; Trace Biosciences Pty Ltd), $0.4 \mu \mathrm{g} / \mathrm{ml}$ hydrocortisone, $5 \mu \mathrm{g} / \mathrm{ml}$ insulin, $5 \mu \mathrm{g} / \mathrm{ml}$ transferrin, $0.02 \mathrm{nM}$ tri-iodothyronine, $180 \mu \mathrm{M}$ adenine, $5.3 \times 10^{-11} \mathrm{M}$ selenius acid, $50 \mu \mathrm{g} / \mathrm{ml}$ gentamycin, 1.88 $\mathrm{mM} \mathrm{CaCl}_{2}$, and $2 \times 10^{-8} \mathrm{M}$ progesterone (Sigma-Aldrich, St. Louis, Missouri, USA). The cultures were raised to the air-medium interface and cultured for another 2 weeks. For the first week, the culture medium was a 1:1 mix of DMEM and Ham's F12 with 2\% FCS and supplements as described above. This medium was modified to lower the serum content to $1 \%$ FCS in the second week. Organotypic cultures were harvested at day 4 just prior to airlift and at day 14 after airlift and processed for both cryosections and paraffin embedding.

Immunostaining tissue sections. Cryosections $(5 \mu \mathrm{m})$ were fixed for 30 minutes with a buffered formalin solution $(2 \%)$ containing $0.1 \mathrm{M}$ sodium cacodylate and sucrose (for immunolocalization of integrins) or for $10 \mathrm{~min}$ utes in a $4 \%$ formalin/PBS solution. The sections were blocked for 30 minutes in $3 \%$ normal goat serum in PBS with $0.05 \%$ Tween- 20 before incubation with the primary Ab. For dual-color fluorescence, both primary $\mathrm{Ab}$ 's were added at the same time and incubated at room temperature for 1 hour, and fluorochrome-conjugated secondary $\mathrm{Ab}$ was incubated for 1 hour. Nuclei were counterstained with $0.1 \mu \mathrm{g} / \mathrm{ml}$ of propidium iodide for 1 minute. All slides were mounted with VECTASHIELD (Vector Laboratories, Burlingame, California, USA) and viewed with an Olympus BX51.

In vitro proliferation assay. Twenty-four-well culture plates were coated with $2 \%$ BSA, human collagen IV (20 $\mu \mathrm{g} / \mathrm{ml}$; Sigma-Aldrich), or human placental LN-10/11 $(5 \mu \mathrm{g} / \mathrm{ml}$; Life Technologies Inc.) as described previ- ously (36). Primary $\alpha_{6}{ }^{\text {dim }}$ and $\alpha_{6}{ }^{\text {bri }}$ keratinocytes were separated by FACS and seeded at $5 \times 10^{3}$ cells/well in precoated wells in keratinocyte growth medium (KBM; Clonetics Corp., San Diego, California, USA) supplemented with $10 \mathrm{ng} / \mathrm{ml} \mathrm{EGF,} 5 \mu \mathrm{g} / \mathrm{ml}$ insulin, 0.5 $\mu \mathrm{g} / \mathrm{ml}$ hydrocortisone (Sigma-Aldrich), and $70 \mu \mathrm{g} / \mathrm{ml}$ bovine pituitary extract (Hammond Cell Tech, Windsor, California, USA).

Keratinocyte differentiation assay. Keratinocytes were seeded at $3 \times 10^{4} /$ well in triplicate uncoated wells (control) or wells precoated with $5 \mu \mathrm{g} / \mathrm{ml} \mathrm{LN}-10 / 11$ and cultured at $37^{\circ} \mathrm{C}$ for up to 6 days in KGM. On day 2 and 6 , cells from triplicate wells were harvested by trypsinization, counted, and lysed in reducing buffer $(0.125 \mathrm{M}$ Tris-HCL, pH $6.8 ; 2.5 \% \mathrm{wt} / \mathrm{vol}$ SDS; $0.01 \% \mathrm{wt} / \mathrm{vol}$ bromophenol blue; $20 \% \mathrm{wt} /$ vol glycerol; $0.72 \mathrm{M} \beta$-mercaptoethanol). Cell extracts $\left(10^{4}\right.$ cells per sample) were resolved by SDS-PAGE on an $8 \%$ gel under reducing conditions, and Western blot analysis for involucrin was performed as described previously (19).

Transplantation assay. Tracheas from 200-250 g Sprague-Dawley rats (purchased from The Institute of Medical and Veterinary Science, Adelaide, Australia), were trimmed and devitalized by three cycles of freezing and thawing $\left(-70^{\circ} \mathrm{C}\right.$ and $\left.37^{\circ} \mathrm{C}\right)$ and then were stretched and secured onto microbore polytetrafluoroethylene tubing (Cole-Parmer Instrument Company, Vernon Hills, Illinois, USA), their ends sealed by LT200 Ligaclips (Ethicon Endo-Surgery, Cincinnati, Ohio, USA). KSCs, TA cells, or differentiating cells $\left(10^{4}\right)$ were inoculated into each trachea, together with $5 \times 10^{5}$ lethally irradiated (15 Gy) cultured keratinocytes as support cells, through a small incision. The tracheas were resealed and implanted subcutaneously into 9- to 12-week-old SCID mice under anesthesia, and were harvested at 6 and 10 weeks after transplantation. Tracheas were processed for routine paraffin embedding and histology. Two replicates were performed for each time point and fraction per experiment.

\section{Results}

Epidermal regeneration from fractionated basal keratinocytes in organotypic cultures. To determine the epidermal regenerative capacity of enriched KSCs $\left(\alpha_{6}{ }^{\text {bri }} \mathrm{CD} 71^{\mathrm{dim}}\right)$, TA cells $\left(\alpha_{6}{ }^{\text {bri }} \mathrm{CD} 71^{\text {bri }}\right)$, and differentiating cells $\left(\alpha_{6}{ }^{\mathrm{dim}}\right)$, primary cell preparations of neonatal foreskin keratinocytes were subjected to cell-surface immunostaining and FACS analysis as described previously (18). Keratinocytes from each fraction $\left(4.5 \times 10^{4}\right)$ were placed directly into parallel organotypic cultures on DEs constructed with p7 fibroblasts derived from human neonatal foreskin in accord with published methods $(35,37)$.

Figure 1 shows representative results $(n=3)$ from histological and immunofluorescent analysis of organotypic cultures derived from KSCs, TA cells, and differentiating cells, as well as UF keratinocytes, which provided a positive control. UF primary keratinocytes gave rise to a multilayered epithelium (Figure 1a) with an integrin-positive basal layer (Figure 1b), suprabasal 

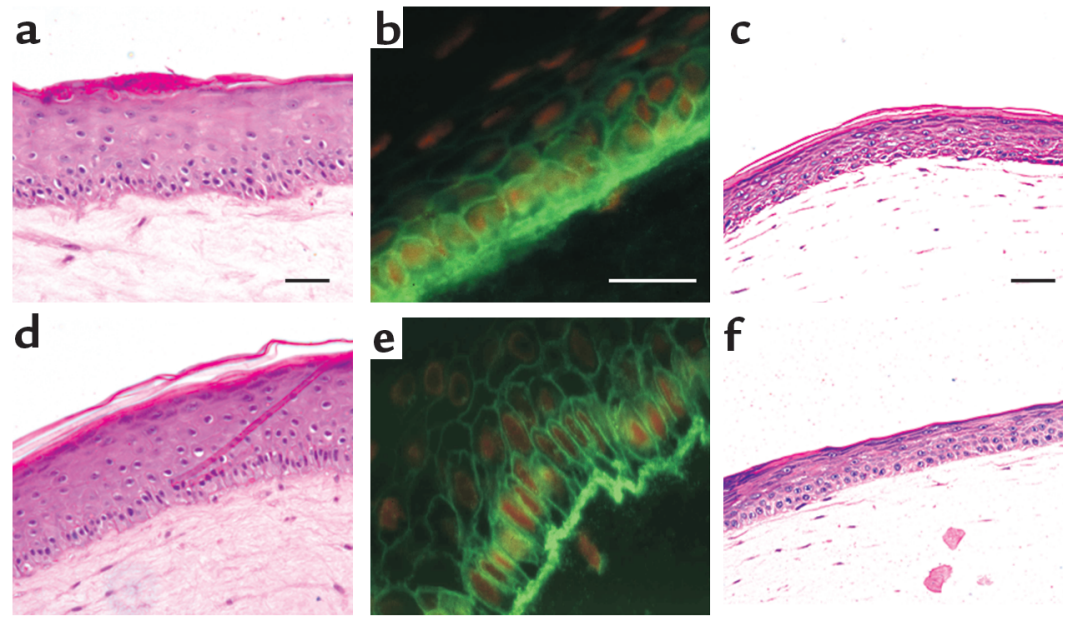

f
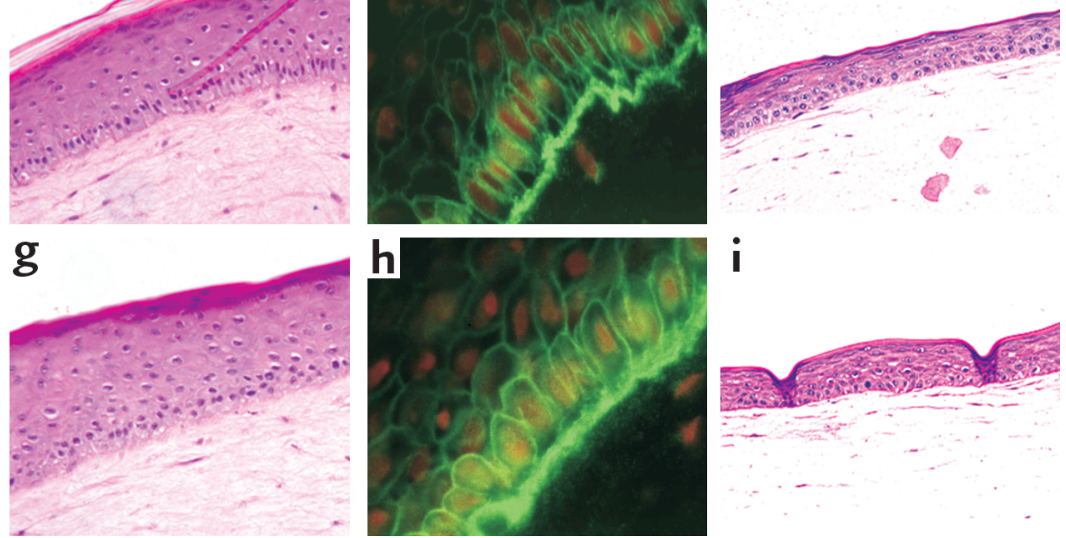

i
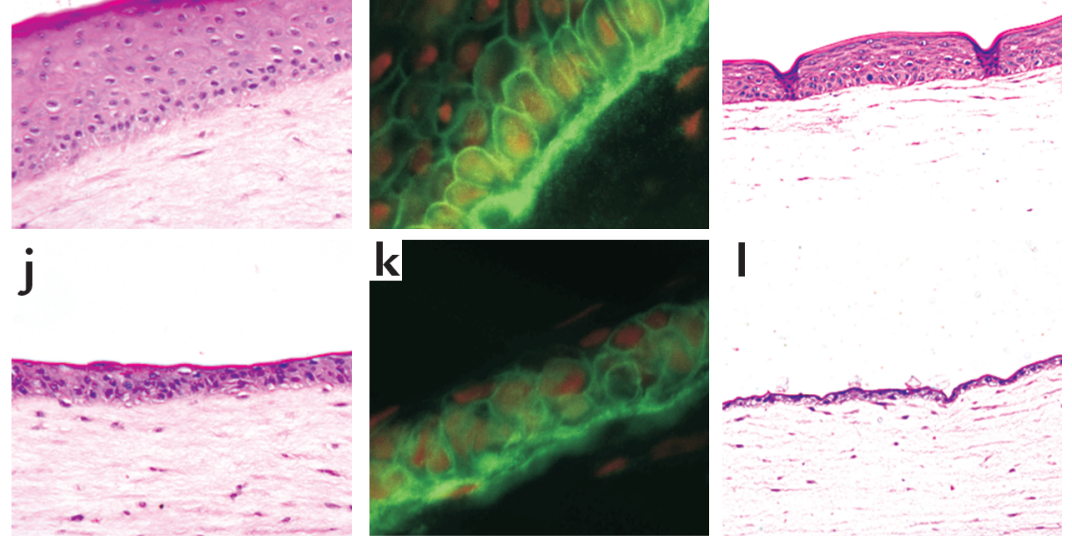

\section{Figure 1}

KSCs and TA cells regenerate epithelial tissue better than differentiating keratinocytes when cocultured with p7 dermal cells. Comparative in vitro tissue-regenerative ability of UF cells $(\mathbf{a}-\mathbf{c}), \mathrm{KSCs}(\mathbf{d}-\mathbf{f})$, TA cells $(\mathbf{g}-\mathbf{i})$, and differentiating epidermal cells $(\mathbf{j}-\mathbf{I})$ in organotypic cultures obtained from $4.5 \times 10^{4}(\mathbf{a}, \mathbf{d}, \mathbf{g}$, and $\mathbf{j})$ versus $10^{4}$ fractionated keratinocytes $(\mathbf{c}, \mathbf{f}, \mathbf{i}$, and I) plated on DEs containing p7 dermal fibroblasts, all harvested at 14 days. Note the relatively poor tissue-regenerative ability of the differentiating $\alpha_{6}$ dim cells $(j)$, which was further decreased by reducing the number of keratinocytes plated to $10^{4}(\mathbf{I})$. Expression of $\alpha_{6}$ integrin ( $\mathbf{b}, \mathbf{e}, \mathbf{h}$, and $\mathbf{k})$ in the cultures corresponding to $\mathbf{a}, \mathbf{d}, \mathbf{g}$, and $\mathbf{j}$ revealed that an integrin-positive basal layer (most polarized in the KSC sheet) was present in the epithelium generated from all fractions as well as total UF keratinocytes. Nuclei were counterstained with propidium iodide. Scale bars: $50 \mu \mathrm{m}$. layers, and terminally differentiated cornified layers. In contrast, fractionated keratinocytes yielded characteristically distinct epithelial sheets predictive of their compartment of origin (Figure 1, d, g, j). The KSC fraction exhibited the most morphologically normal epidermis with a well-organized polarized basal layer and differentiating suprabasal layers (Figure 1d). Interestingly, TA cells were also capable of regenerating a multilayered epidermis (Figure 1g), and the sheets contained an integrin-positive basal layer (Figure 1h) and differentiated suprabasal layers. This result is contrary to the dogma that only stem cells are capable of epithelial regeneration. In contrast, the $\alpha_{6}{ }^{\mathrm{dim}}$ keratinocytes predictably showed a limited capacity to regenerate epithelial tissue (Figure 1j), as expected of a keratinocyte population shown to express keratin 10 and involucrin, with a relatively poor initial colony-forming efficiency in vitro $(18,19)$. A less-distinct basal layer was generated by these cells with more diffuse expression of the $\alpha_{6}$ integrin throughout the sheet (Figure 1k), and fewer layers of epithelium were produced prior to terminal differentiation.

Tissue-regenerative ability of $\alpha_{6}{ }^{\operatorname{dim}}$ keratinocytes can be severely compromised by decreasing the keratinocyte cell number plated on $p 7 D E s$. To further verify that the fractionated keratinocyte subpopulations (KSCs, TA cells, and differentiating cells) had distinct intrinsic tissue-regenerative properties, we tested the effects of decreasing the number of input keratinocytes to $10^{4}$ per organotypic culture, using p7 dermal cells in the DE. We reasoned that this would make a greater demand for proliferation from the fractions being tested and that any intrinsic differences between these populations would be more evident. The data show that the UF, KSC, and TA fractions (Figure 1, c, f, i) performed reasonably well, although the effect of plating fewer cells was evident in the overall decreased thickness of the epithelium. Under these conditions, the $\alpha_{6}{ }^{\text {dim }}$ differentiating keratinocytes were clearly distinguishable from the KSC and TA fractions, exhibiting their inability to proliferate and regenerate epithelial tissue (Figure 11).

Epithelial regenerative capacity of $\alpha_{6}^{\text {dim }}$ differentiating keratinocytes can be modulated by using minimally cultured dermal cells in the DE. In the course of our experimentation, we sought to determine the epidermal regenerative ability of fractionated keratinocytes in conditions as close to the in vivo microenvironment as possible. Specifically, we chose to incorporate minimally cultured neonatal foreskin-derived dermal cells into the DEs (rather than p7) prior to seeding the fractionated keratinocytes. Figure 2 shows epithelial regeneration obtained from UF cells, KSCs, TA cells, 


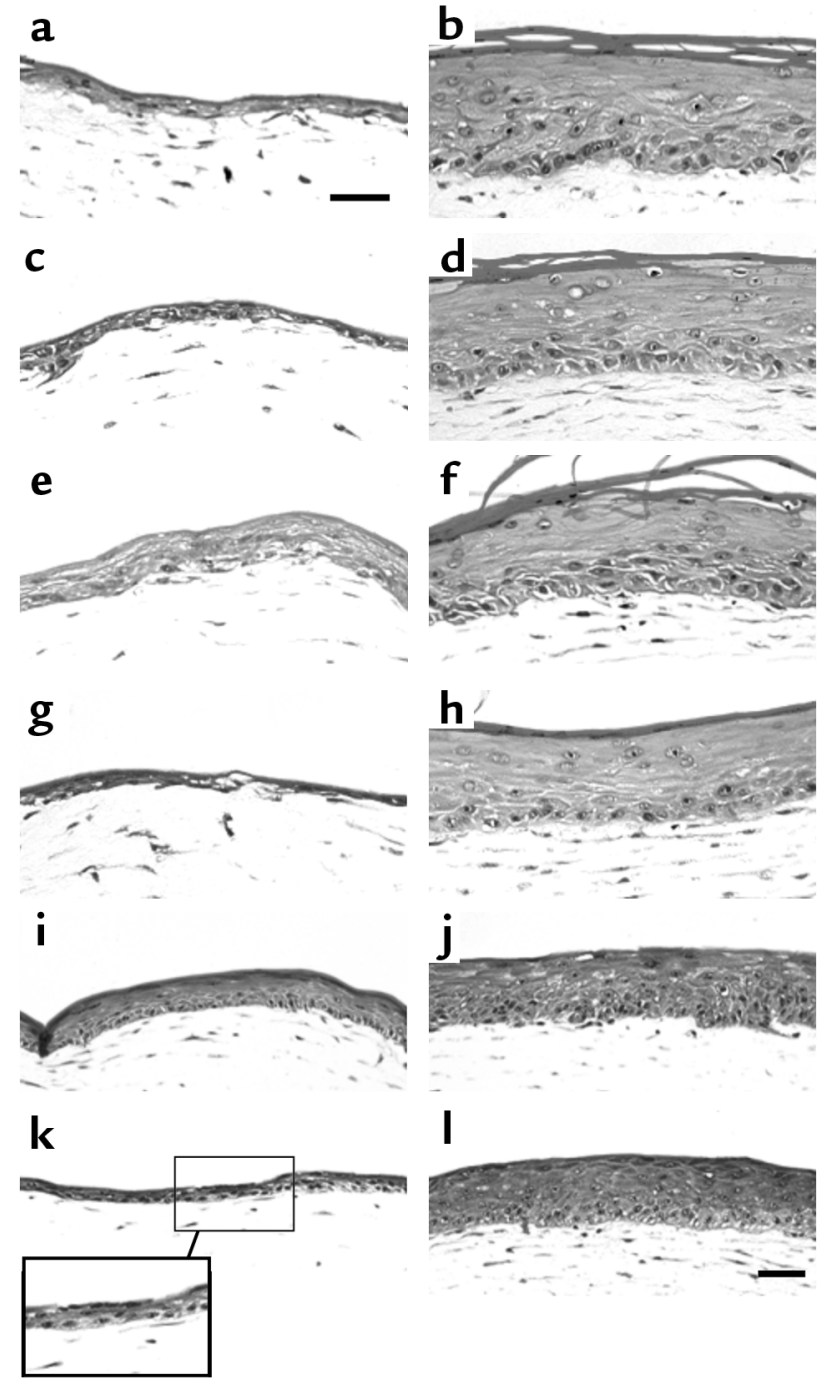

and differentiating cells in a typical organotypic experiment $(n=3)$ using $\mathrm{p} 1$ dermal cells in the DE. Histological analysis at 4 days (that is, at the end of the submerged culture period) revealed that while the UF cells, KSCs, and differentiating cells showed limited epithelialization at this early stage (Figure 2, a, c, g), the TA cells had already regenerated a comparatively thicker epithelium (Figure 2e). Importantly, after the cells were cultured for 14 days at the air-liquid interface to allow differentiation and stratification, all fractions, including differentiating cells, were equally capable of regenerating a morphologically and histologically normal stratified epithelium of similar thickness (Figure 2, b, d, f, h). This observation was surprising and contrary to our assumption that only stem cells would have the ability to regenerate their tissue of origin, while their progeny would be irreversibly committed to differentiation. These results were consistently observed in several replicate experiments $(n=3)$. Importantly, the differences in regenerative capacity of the $\alpha_{6} \mathrm{dim}$ differentiating keratinocytes were reproduced in experiments where cells

\section{Figure 2}

KSCs and their progeny exhibit equivalent epidermal tissue-regenerative capability when cocultured with early-passage dermal cells. (a-h) Epithelial tissue regeneration in organotypic cultures obtained from $4.5 \times 10^{4} \mathrm{UF}$ cells ( $\mathbf{a}$ and $\left.\mathbf{b}\right), \mathrm{KSCs}$ ( $\mathbf{c}$ and $\left.\mathbf{d}\right)$ ), TA cells (e and $\mathbf{f}$ ), and differentiating cells ( $\mathbf{g}$ and $\mathbf{h}$ ) on dermal equivalents populated with $\mathrm{p} 1$ foreskin dermal cells ( 1 DEs) analyzed at day 4 (prior to lifting to the air-liquid interface; see a, c, e, and $\mathbf{g}$ ) and at day 14 after airlift (b, $\mathbf{d}, \mathbf{f}$, and $\mathbf{h})$. Note that the actively cycling TA cells had regenerated a thicker epithelium compared with the other fractions of keratinocytes by day 4 (e). By day 14, however, all fractions, including differentiating cells, had regenerated an epithelium of similar thickness and cellularity. Scale bar: $50 \mu \mathrm{m}$. (i-I) Coculture with minimally passaged dermal cells enhances the epidermal regenerative capacity of low numbers of differentiating $\alpha_{6}$ dim basal keratinocytes. Here, $4.5 \times 10^{4}$ (i and $\mathbf{j}$ ) or $10^{4} \alpha_{6}$ dim cells ( $\mathbf{k}$ and $\mathbf{I}$ ) collected from a single FACS experiment were placed simultaneously in organotypic cultures consisting of either $\mathrm{p} 7 \mathrm{DEs}$ ( $\mathbf{i}$ and $\mathbf{k}$ ) or $\mathrm{p} 1 \mathrm{DEs}$ ( $\mathbf{j}$ and $\mathbf{I}$ ) and were harvested at day 14 after airlift. H\&E-stained sections of these cultures show that while the tissue regeneration obtained from $\alpha_{6}{ }^{\mathrm{dim}}$ cells on the p7 DEs (i) can be compromised by decreasing the number of keratinocytes plated to $10^{4}(\mathbf{k})$, this can be compensated for by coculture with p 1 DEs (I). Inset: higher magnification of regenerated epidermis from differentiating cells shown in k. Scale bar: $50 \mu \mathrm{m}$.

from the same skin samples and cell-sorting procedure were placed simultaneously in organotypic cultures with either $\mathrm{p} 7$ or $\mathrm{p} 1$ dermal cells (Figure 2, i and j). The potent growth-stimulatory effects of early-passage dermal cells could be further demonstrated by improving epithelial tissue regeneration from low numbers $\left(10^{4}\right)$ of $\alpha_{6}{ }^{\text {dim }}$ keratinocytes on $\mathrm{p} 7$ (Figure $2 \mathrm{k}$ ) compared with p1 (Figure 2l) dermal cells.

We then set out to determine if the morphologically identical epidermal sheets regenerated by the KSC, TA, and differentiating fractions on $\mathrm{p} 1$ dermal cells underwent an appropriate program of epidermal differentiation in terms of their temporal and spatial expression of keratinocyte markers. Immunofluorescent staining revealed that all epidermal sheets contained a $\beta_{1}$ integrin-positive basal layer (Figure 3, j-1) and expressed appropriate markers of keratinocyte differentiation in the suprabasal layers, including keratin 10 (Figure 3, $a-c$ ), involucrin (Figure $3 \mathrm{~d}-\mathrm{f}$ ), and filaggrin (Figure 3, $\mathrm{g}-\mathrm{i})$, indicating that all keratinocyte fractions had undergone appropriate epidermal maturation.

These data demonstrate that the KSC and TA fractions have an intrinsically high ability to regenerate epithelium in this assay, irrespective of the use of earlypassage ( $\mathrm{p} 1$ ) or late-passage ( $\mathrm{p} 7)$ dermal cells in the DEs. In contrast, the tissue-regenerative capacity of $\alpha_{6}{ }^{\text {dim }}$ keratinocytes could be significantly enhanced by coculture with early-passage dermal cells.

Epidermal stem cells establish the most "normal" epidermis in organotypic cultures. It is widely documented that K6 and $\mathrm{K} 16$ are not expressed by normal interfollicular epidermal cells. Their expression, however, can be induced in hyperproliferative conditions such as psoriasis $(38,39)$ and wound healing $(40,41)$ and in 

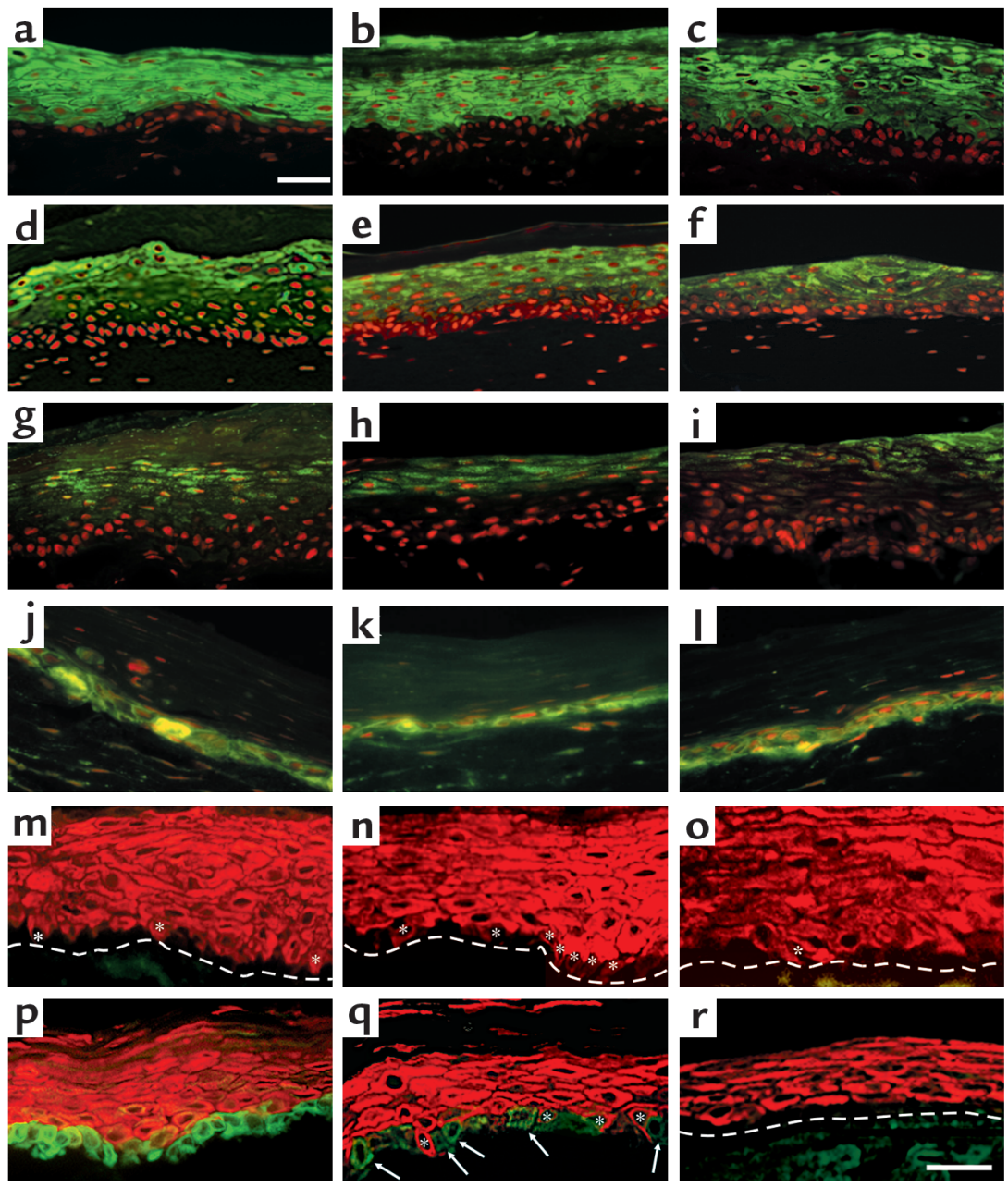
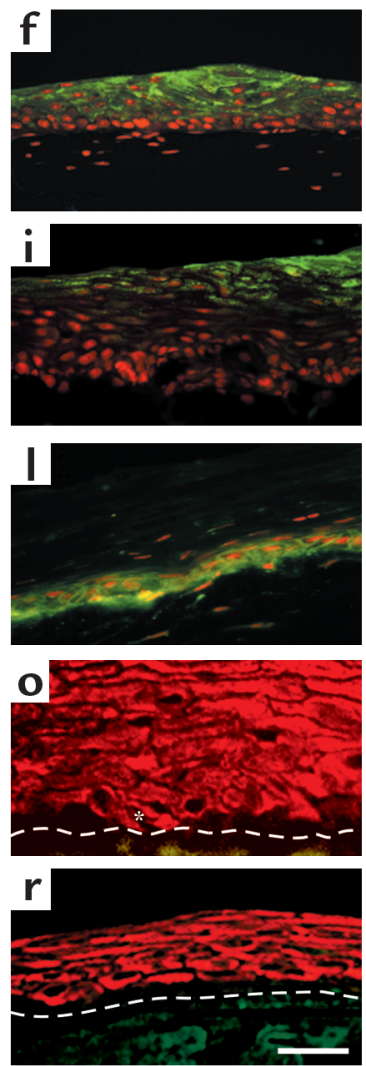

Figure 3

Epithelial sheets generated from all fractions (KSCs, TA cells, and differentiating cells) exhibit appropriate temporal and spatial expression of differentiation markers. (a-I) Epithelial tissue regenerated by $4.5 \times 10^{4} \mathrm{KSCs}(\mathbf{a}, \mathbf{d}, \mathbf{g}$, and $\mathbf{j})$, TA cells ( $\mathbf{b}, \mathbf{e}, \mathbf{h}$, and $\mathbf{k})$, and differentiating cells $(\mathbf{c}, \mathbf{f}, \mathbf{i}$, and $\mathbf{I})$ cocultured with $\mathrm{p} 1 \mathrm{DEs}$ express the differentiation markers $\mathrm{K} 10(\mathbf{a}-\mathbf{c})$, involucrin ( $\mathbf{d}-\mathbf{f})$, and filaggrin $(\mathbf{g}-\mathbf{i})$ suprabasally and contain a $\beta_{1}$ integrin-positive basal layer $(j-I)$. Nuclei were counterstained with propidium iodide. (m-r) Epithelial sheets derived from epidermal stem cells reexpress K15 uniformly in the basal layer. Organotypic cultures generated by KSCs ( $\mathbf{m}$ and $\mathbf{p})$, TA cells ( $\mathbf{n}$ and $\mathbf{q}$ ), and differentiating cells ( $\mathbf{o}$ and $\mathbf{r}$ ) on $\mathrm{p} 1$ DEs (m-o) and p7 DEs (p-r) at day 14, stained for K15 (FITC) and K16 (Texas red). Suprabasal K16 expression was observed in epithelium derived from all fractions under all conditions, indicating that the keratinocytes were activated in these cultures. K15 expression was only detected when basal keratinocytes were cultured on $\mathrm{p} 7 \mathrm{DEs}$ and not on p1 DEs. Notably, intense staining for K15 uniformly in the basal layer (as observed in foreskin epidermis in vivo) was observed only in the $\mathrm{KSC} / \mathrm{p} 7 \mathrm{DE}$ culture (p). Many of the basal cells of the TA sheet weakly expressed K15 (q), while the differentiating cells were negative for K15 $(\mathbf{r})$. Dotted line indicates the dermo-epidermal junction. Asterisks indicate K16-positive basal cells. Arrows indicate K15-positive basal cells. Scale bar: $50 \mu \mathrm{m}$. organotypic cultures (42), indicating that these keratins are markers of activated keratinocytes. In contrast, K15, normally expressed by basal keratinocytes in neonatal foreskin, becomes downregulated in psoriatic skin (42) and is lost in organotypic cultures (42). Thus, the expression of K15 and K16 was determined in epithelial sheets generated from all fractions of keratinocytes as indicators of tissue homeostasis and activation, respectively. Abundant suprabasal K16 expression was observed in epithelial sheets generated with KSCs, TA cells, and differentiating cells cocultured with p1 DE, while K15 expression was undetectable (Figure 3, m-o). Thus, these epithelial sheets contained keratinocytes in an activated state. These results are consistent with findings by Waseem et al. (42), who also did not detect any expression of K15 in skin equivalents generated by human keratinocytes seeded on primary dermal fibroblasts.

In the presence of $\mathrm{p} 7 \mathrm{DEs}$, the epithelial sheets derived from all keratinocyte fractions continued to express K16 in suprabasal cells, reflecting their activated state. Importantly, reexpression of K15 in the basal layer was observed (Figure 3, p and q). Notably, the KSC-derived epithelial sheet expressed K15 uniformly in the basal layer (Figure 3p), as reported for neonatal foreskin tissue, while those derived from the TA fraction exhibited sporadic reexpression of K15 in the basal layer (Figure 3q). Significantly, the differentiating cells did not express K15 (Figure 3r). Thus, the trend toward establishing homeostasis (i.e., reexpression of K15) was exhibited to the greatest extent in KSCs and least extent in differentiating cells in the presence of $\mathrm{p} 7$ DEs. These data indicate that the $\alpha_{6}{ }^{\text {bri CD71 }}{ }^{\text {dim }}$ stem cell population can be distinguished by its ability to return to a relatively homeostatic state compared with the TA and differentiating population under these conditions. This can be prevented, however, by coculture with early-passage dermal cells (which may secrete more or qualitatively different proproliferative factors than the $\mathrm{p} 7$ dermal cells), consistent with their ability to elicit greater proliferation from the $\alpha_{6}{ }^{\mathrm{dim}}$ differentiating keratinocytes.

Poor tissue-regenerative ability of $\alpha_{6}{ }^{\operatorname{dim}}$ keratinocytes is correlated with the absence of the ECM protein $L N-10 / 11$ in organotypic cultures. We have shown recently that the ECM proteins LN-10/11 found in epidermal basement membranes is an important adhesive ligand for keratinocytes in vitro. Furthermore, adhesion to LN-10/11 stimulates the proliferation of cultured neonatal, adult, and transformed human keratinocytes in monolayer 

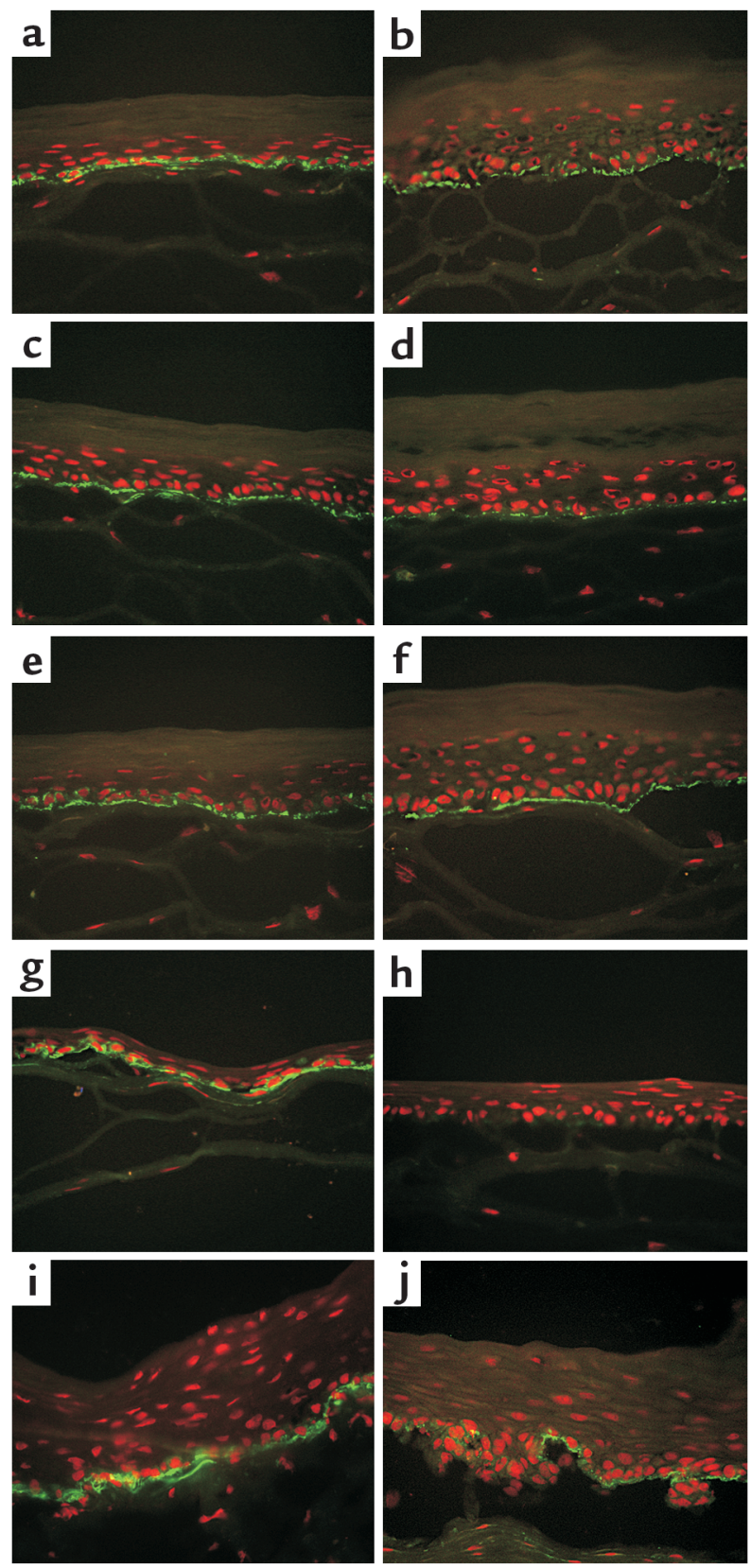

cultures (43). Organotypic cultures from all fractions cocultured with $\mathrm{p} 1$ or $\mathrm{p} 7 \mathrm{DEs}$ were subjected to immunofluorescent staining for the two best-studied laminin isoforms in skin, that is, $\mathrm{LN}-5$ ( $\alpha 3$ chain) and LN-10/11 ( $\alpha 5$ chain). LN-10/11 was detected in the dermal-epidermal junction of epithelial sheets derived from all populations exhibiting good epithelial regenerative ability, that is UF, KSC, and TA fractions cocultured with $\mathrm{p} 1$ (data not shown) or $\mathrm{p} 7 \mathrm{DE}$ (Figure $4, b, d, f)$ and $\alpha_{6}{ }^{\text {dim }}$ differentiating keratinocytes cocultured with p1 DE (Figure 4j). Interestingly, LN-10/11 was absent under conditions where poor epithelial regeneration was observed (i.e., $\alpha_{6}{ }^{\mathrm{dim}}$ cells cocultured with $\mathrm{p} 7$ DEs; Figure $4 \mathrm{~h}$ ). Notably, LN-5 was present in all epithelial sheets,

\section{Figure 4}

Expression of $\mathrm{LN}-10 / 11$ but not $\mathrm{LN}-5$ correlates with the increased ability of differentiating keratinocytes to regenerate epithelium. Organotypic cultures (day 14) generated by $4.5 \times 10^{4}$ UF keratinocytes ( $\mathbf{a}$ and $\mathbf{b}$ ), KSCs ( $\mathbf{c}$ and $\mathbf{d}$ ), TA keratinocytes (e and $\mathbf{f}$ ), and differentiating keratinocytes $(\mathbf{g}$ and $\mathbf{h})$ seeded on $\mathrm{p} 7 \mathrm{DEs}(\mathbf{a}-\mathbf{h})$ or $\mathbf{p} 1$ DEs ( $\mathbf{i}$ and $\mathbf{j}$ ) stained for LN-5 $\alpha 3$ chain (FITC: $\mathbf{a}, \mathbf{c}, \mathbf{e}, \mathbf{g}$, and $\mathbf{i}$ ) and LN-10/11 $\alpha 5$ chain (FITC: $\mathbf{b}, \mathbf{d}, \mathbf{f}, \mathbf{h}$, and $\mathbf{j}$ ). Nuclei were counterstained with propidium iodide. LN-5 expression was detected in all cultures regardless of the extent of tissue regeneration ( $\mathbf{a}, \mathbf{c}, \mathbf{e}, \mathbf{g}$, and i); in contrast, $\mathrm{LN}-10 / 11$ expression was observed in all cases where good tissue regeneration was obtained $(\mathbf{b}, \mathbf{d}, \mathbf{f}$, and $\mathbf{j}$ ), but was absent from cultures of $\alpha_{6}{ }^{\mathrm{dim}}$ cells on $\mathrm{p} 7 \mathrm{DE}(\mathbf{h})$, which exhibited limited tissue regeneration. Scale bar: $50 \mu \mathrm{m}$.

regardless of the keratinocyte fractions or dermal cells included (Figure 4, a, c, e, g, i), showing no correlation with tissue-regenerative ability.

$L N-10 / 11$ promotes the proliferation of $\alpha_{6}^{\text {dim }}$ keratinocytes and delays differentiation. In view of our recent observations that $\mathrm{LN}-10 / 11$ promotes the proliferation of cultured keratinocytes (43), we examined whether this was also the case for primary keratinocytes, particularly the $\alpha_{6}$ dim differentiating fraction. Primary keratinocytes fractionated into $\alpha_{6}{ }^{\text {bri }}$ (consisting of KSCs and TA cells) and $\alpha_{6} \mathrm{dim}$ (differentiating) keratinocytes were plated on control-coated (BSA), collagen IV-coated, or LN-10/11-coated wells and cultured in complete medium for 12 days. Consistent with what was shown in our previously published work (18), the $\alpha_{6}^{\text {bri }}$ cells clearly demonstrated greater growth potential than the $\alpha_{6}{ }^{\mathrm{dim}}$ keratinocytes (Figure 5, a and b; BSA wells). The proliferation of $\alpha_{6}$ bri cells was clearly enhanced by plating on either collagen IV or LN-10/11 (Figure 5a). The $\alpha_{6}{ }^{\operatorname{dim}}$ fraction was also stimulated to proliferate better on these ECMs, although LN-10/11 recruited more keratinocytes into proliferation compared with collagen IV (Figure 5b). Daily microscopic analysis of both fractions of cells plated on LN-10/11 revealed that greater numbers of cells adhered and initiated keratinocyte colonies on this substrate compared with BSA controls, although it was difficult to obtain quantitative data on clonal expansion of these colonies on $\mathrm{LN}-10 / 11$ due to their tendency to migrate on this substrate, as previously reported by us for cultured keratinocytes (43). We further observed that keratinocyte differentiation can be delayed by plating cells on a $\mathrm{LN}-10 / 11$ substrate, as determined by the levels of involucrin expression determined by Western blot analysis. Thus, keratinocytes plated on LN-10/11 expressed about sevenfold lower levels of involucrin at day 2 (and about twofold lower levels on day 6) after seeding compared with controls (Figure $5 c ; n=2$ ). Although differentiation was not inhibited, it appeared to be delayed because cells continued to proliferate. These data suggested that the absence of LN-10/11 in organotypic cultures of $\alpha_{6}{ }^{\mathrm{dim}}$ cells containing p7 DEs (Figure 4h) may indeed be a limiting factor affecting their tissue-regenerative capacity. 
Exogenous $L N-10 / 11$ restores the poor tissue-regenerative ability of $\alpha_{6}{ }^{\text {dim }}$ cells cocultured on $p 7$ DEs in organotypic cultures. To test the direct role of $\mathrm{LN}-10 / 11$ in regulating epithelial tissue regeneration, organotypic cultures of $\alpha_{6}{ }^{\text {dim }}$ keratinocytes were established with $\mathrm{p} 7$ DEs previously shown to perform poorly (Figure 1, j and 1 ) with the addition of exogenous LN-10/11. Specifically, the collagen gels were coated with $10 \mu \mathrm{g} / \mathrm{ml}$ of LN-10/11 prior to seeding epidermal cells, and the keratinocytes were resuspended in LN-10/11 before being placed into the organotypic cultures. Predictably, in the absence of exogenous LN-10/11, the $\alpha_{6}$ bri fraction (consisting of KSCs and TA cells) exhibited an excellent intrinsic capacity for tissue regeneration as expected (Figure 5d; positive control), although an improvement was evident in the presence of LN-10/11 (Figure 5e). The comparatively poor regenerative capacity of $\alpha_{6}{ }^{\mathrm{dim}}$ cells (Figure $5 f$ ) was significantly improved by the addition of exogenous LN-10/11, resulting in the production of a multilayered epithelium (Figure $5 \mathrm{~g}$ ). These data were reproduced in two independent experiments and demonstrate that $\mathrm{LN}-10 / 11$ is an important regulator of epithelial tissue regeneration, capable of returning keratinocytes to a proliferative state despite the initiation of terminal differentiation.

Epidermal regeneration from fractionated basal keratinocytes in vivo following transplantation. Given that the organotypic culture model is a short-term assay for tissue regeneration, we sought to determine the longterm tissue-regenerative ability of KSCs, TA cells, and differentiating cells. It has been demonstrated previously that in vivo transplantation of epidermal cells improves the growth and differentiation of these cells and results in sustained engraftment for periods of up to a year (14), suggesting that additional factors absent from the in vitro model are provided by the in vivo environment. We have optimized an in vivo transplantation model originally developed by Terzaghi et al. (44) and used recently for propagating murine epidermis (45), which permits us to assay long-term tissue regeneration derived from small numbers of FACS-isolated primary epidermal cells. Thus, $10^{4}$ freshly isolated human KSCs, TA cells, or differentiating cells (together with $5 \times 10^{5}$ cultured keratinocytes that had been lethally irradiated with 15 Gy) were inoculated into de-epithelialized rat tracheas (achieved by repeated cycles of freezing and thawing), and their ability to cover the tracheal lumen with a multilayered epithelium was determined histologically for up to 10 weeks following subcutaneous transplantation into SCID mice. Histological analysis of transverse sections of tracheas inoculated with primary KSCs (Figure 6, a, d, g, j), TA cells (Figure 6, b, e, $\mathrm{h}, \mathrm{k}$ ), or differentiating cells (Figure $6, \mathrm{c}, \mathrm{f}, \mathrm{i}, \mathrm{l}$ ) analyzed at 6 and 10 weeks after transplantation revealed that all three fractions were capable of re-epithelializing the lumen with a morphologically normal epidermis that maintained itself while giving rise to mature differentiated cells (cornified cells) over the time peri- od analyzed. Although a thicker epithelium was obtained from all fractions at 6 weeks compared with 10 weeks, no significant differences were observed between the KSC, TA, and differentiating cell derived epithelial sheets at the time points analyzed after transplantation. Importantly, no epithelialization was observed when transplanted tracheas were not inoculated (i.e., no keratinocytes; Figure $6 \mathrm{~m}$ ) or inoculated

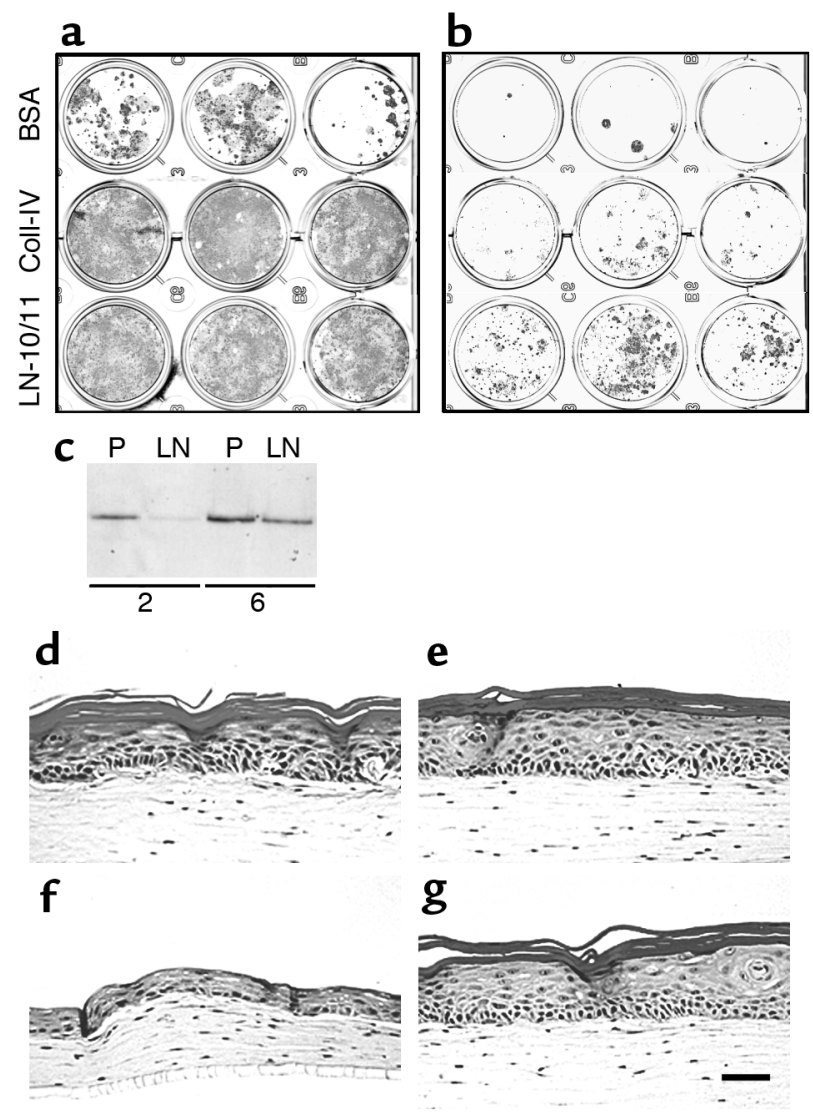

\section{Figure 5}

$\mathrm{LN}-10 / 11$ is a potent proliferative substrate for $\alpha_{6}$ dim differentiating keratinocytes, delays terminal differentiation in vitro, and promotes epidermal tissue regeneration, particularly from $\alpha_{6}{ }^{\text {dim }}$ cells. Keratinocyte cultures derived from $\alpha_{6}{ }^{\text {bri }}$ (a) and $\alpha_{6}$ dim (b) fractions stained for keratins (AE1/AE3) after 12 days in culture plated on BSA-coated ( $2 \% \mathrm{wt} / \mathrm{vol}$ ), human collagen IV-coated (Coll-IV; 20 $\mu \mathrm{g} / \mathrm{ml})$, or human $\mathrm{LN}-10 / 11$-coated $(5 \mu \mathrm{g} / \mathrm{ml})$ wells. While $\alpha_{6}$ bri cells were stimulated to grow on both collagen IV and LN-10/11, the poor proliferative capacity of $\alpha_{6}$ dim cells was significantly improved on a LN-10/11 substrate (b). Western blot analysis showing decreased involucrin expression (c) in UF cultured keratinocytes seeded on $\mathrm{LN}-10 / 11$ (LN; $5 \mu \mathrm{g} / \mathrm{ml}$ ) compared with controls (on plastic; P) at day 2 and day 6 following plating. Equivalent numbers of keratinocytes $\left(10^{4}\right)$ were loaded per lane. $(\mathbf{d}-\mathbf{g})$ Organotypic cultures (day 14) of $10^{4} \alpha_{6}^{\text {bri }}$ ( $\mathbf{d}$ and $\mathbf{e}$ ) and $\alpha_{6} \operatorname{dim}(\mathbf{f}$ and $\mathbf{g}$ ) keratinocytes cultured either on $\mathrm{p} 7 \mathrm{DEs}$ alone ( $\mathbf{d}$ and $\mathbf{f}$ ) or on $\mathrm{p} 7 \mathrm{DE}$ with exogenous $\mathrm{LN}-10 / 11$ (e and $\mathbf{g}$ ). H\&E-stained sections show that the exogenous supply of $L N-10 / 11$ known to be absent in $\alpha_{6}$ dim cocultures on $p 7$ DEs (f) enhanced the epithelial regeneration ability of these cells significantly $(\mathbf{g})$. Greater epidermal regeneration was also evident with $\alpha_{6}$ bri cells with the inclusion of LN-10/11 (e), although the effects on $\alpha_{6}{ }^{\mathrm{dim}}$ cells are more dramatic. Scale bar: $50 \mu \mathrm{m}$. 

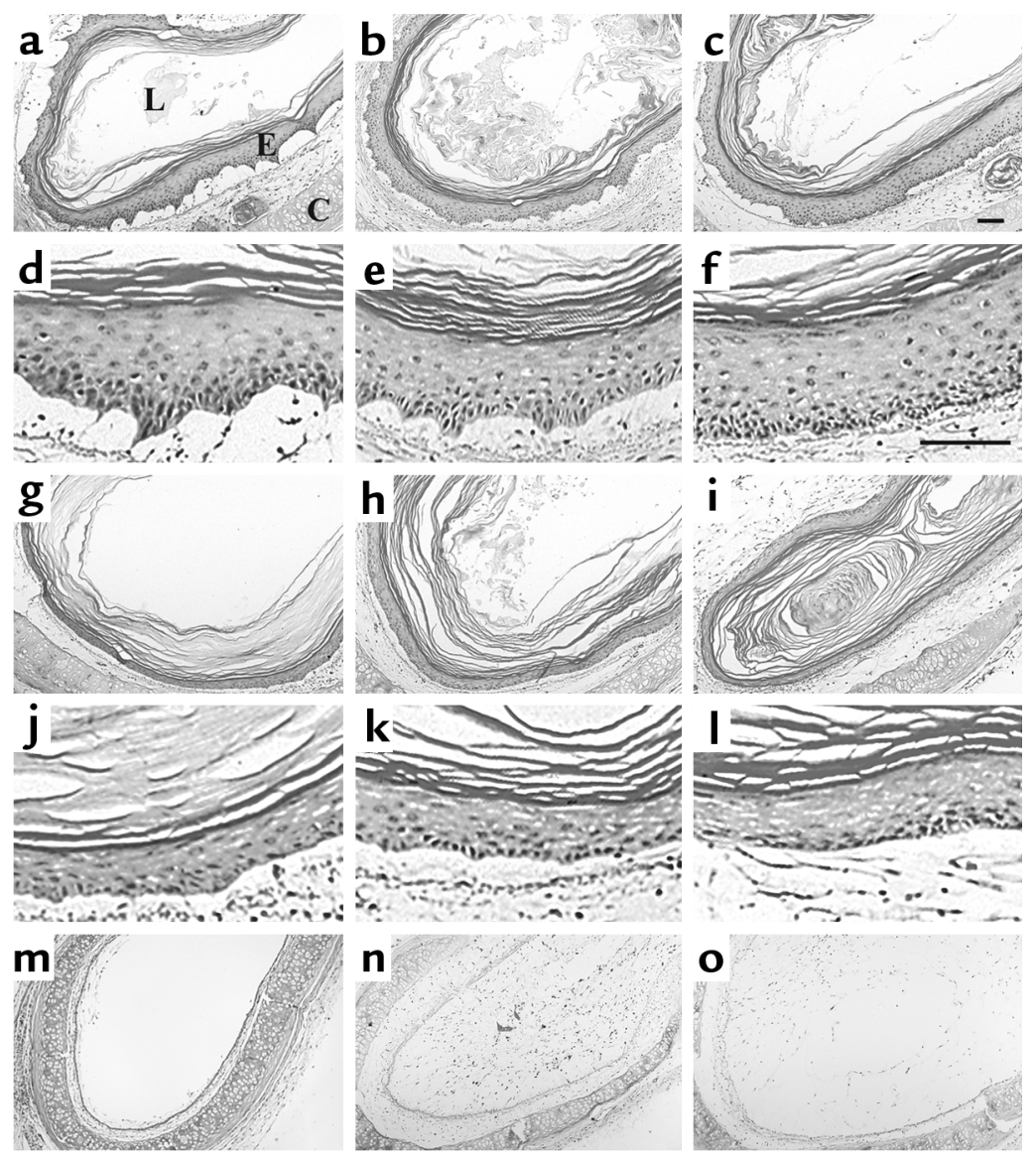

\section{Figure 6}

KSCs and their progeny exhibit equivalent longterm epidermal tissue-regenerative capability in vivo. Transverse histological sections of rat trachea lumens lined with epithelial sheets derived from $10^{4}$ human foreskin KSCs (a, d, g, and j), TA cells ( $\mathbf{b}, \mathbf{e}, \mathbf{h}$, and $\mathbf{k})$, and differentiating cells ( $\mathbf{c}$, $\mathbf{f}, \mathbf{i}, \mathbf{I})$ harvested at 6 weeks (a-f) and 10 weeks (g-I) after transplantation. All fractions were cotransplanted with $5 \times 10^{5}$ cultured keratinocytes that had received 15 Gy irradiation. For negative control transplants, uninoculated trachea at 6 weeks $(\mathbf{m})$ and $5 \times 10^{5}$ irradiated keratinocytes alone at 6 weeks (n) and 10 weeks (o) after transplant did not yield epithelialization. $\times 10$ magnification $(\mathbf{a}-\mathbf{c}, \mathbf{g}-\mathbf{i}$, and $\mathbf{m}-\mathbf{o}) ; \times 40$ magnification (d-f and j-I). Scale bar: $100 \mu \mathrm{m}$. C, cartilage; L, rat trachea lumen, E, epithelial. with the irradiated keratinocytes alone for 6 weeks (Figure 6n) or 10 weeks (Figure 6o). These data demonstrate that prolonged tissue regeneration is not an exclusive property of the epidermal stem cell population, but rather can be exhibited by TA cells and early differentiating cells of the epidermis when transplanted into an in vivo setting.

\section{Discussion}

The most important functional definition of any stem cell population is the ability to regenerate its tissue of origin. We therefore set out to determine whether the $\alpha_{6}{ }^{\text {bri }}$ CD71 $1^{\text {dim }}$ human KSC population, known to exhibit many other important stem cell properties $(18,22)$, could be distinguished from their progeny (i.e., $\alpha_{6}{ }^{\text {bri }}$ CD $71^{\text {bri }}$ TA cells and $\alpha_{6}$ dim differentiating cells), initially in an in vitro tissue regeneration assay. Our results demonstrated that epidermal tissue regeneration is dictated by (a) the stage of maturation of the keratinocytes being assayed and (b) the dermal and ECM microenvironment in which these cells are placed. Predictably, the $\alpha_{6}{ }^{\text {bri }}$ CD71 1 dim stem cell fraction possessed the greatest intrinsic tissue-regenerative capacity. This was most clearly demonstrated when all fractions were cocultured with p7 DEs - the KSC fraction regenerated a relatively normal epithelial sheet morphologically and biochemically with a polarized basal layer and uniform expression of K15, indicating a trend toward homeostatic epidermal cell renewal. Contrary to current dogma, however, the $\alpha_{6}{ }^{\text {bri }} \mathrm{CD} 71^{\text {bri }}$ TA population also exhibited as yet unprecedented and impressive epithelialization under all conditions tested. Notably, the TA fraction was distinguished from KSCs and differentiating cells in its ability to regenerate a multilayered epithelial sheet as early as 4 days after placement into organotypic cultures, suggesting that this subpopulation of basal cells is the first to proliferate in response to an epithelial wound in vivo, a logical consequence of their actively cycling state in the tissue. The recruitment of the relatively quiescent stem cell and differentiating populations occurred at a slower rate, presumably reflecting the time required for these cells to reenter the cell cycle. Ultimately, however, all fractions were capable of regenerating a comparable epithelium when cocultured with p1 DEs. Notably, the absence of $\mathrm{LN}-10 / 11$ was a limiting factor restricting the tissue-regenerative capacity of $\alpha_{6}$ dim cells; importantly, coculture with $\mathrm{p} 1$ dermal cells or exogenous supply of this basement membrane protein restored the ability of these committed keratinocytes to regenerate epithelial tissue in this short-term tissue regeneration assay. We concluded that organotypic cultures do not provide an appropriate model system that allows distinction between a transient wound-healing response and sustained tissue regeneration, the latter being a hallmark of stem cells. We therefore tested the 
long-term tissue-regenerative capacity of KSCs, TA cells, and D cells in an in vivo setting and observed that all fractions continued to produce epithelial sheets and accumulate cornified layers within the trachea lumen over a 10-week period (Figure 6). These data clearly demonstrate, we believe for the first time, that extensive proliferative and tissue-regenerative capacity is not an exclusive property restricted to epidermal stem cells, as assumed by many investigators to date, but rather this result can also be obtained from the progeny of the stem cell population. The notion that the ability to regenerate functionally normal tissue is an exclusive property of stem cells is a general assumption in the stem cell biology field and requires reevaluation in the context of the experimental conditions under which tissue regeneration is assayed (i.e., the microenvironment in which cells are placed). Clearly, transplantation of cells into an in vivo environment overcomes the suboptimal conditions or absence of specific growth factors and/or ECM proteins prevalent in in vitro model systems. Our data also call into question the notion that ex vivo cultivation of unfractionated neonatal keratinocytes is solely attributed to the stem cell population and the validity of any in vitro or in vivo epidermal cell assays that purport to measure stem cell activity based on short-term (2-week) colony formation or epidermal tissue regeneration $(16,17)$. A reevaluation of apparent stem cell markers thought to identify candidate stem cell populations based on these assays is warranted in the light of our findings. Whether keratinocyte progenitors from adult human or rodent epithelia retain properties similar to those reported here for neonatal human keratinocytes remains to be determined, however.

Specific microenvironmental factors that have a role in regulating the growth and development of keratinocyte progenitors remain poorly defined. Our analysis of the $\alpha_{6}$ dim fraction revealed that LN-10/11 is a critical component of the inductive microenvironment of keratinocytes, with an important role in promoting epithelial tissue-regenerative capacity, and that detachment from LN-10/11 in the basement membrane is likely to be a key factor in promoting keratinocyte differentiation. Our results indicate that tissue regeneration from all classes of basal keratinocytes may be enhanced when exposed to LN-10/11 in vitro. This observation has strong implications for the ex vivo expansion of keratinocyte progenitors for cellular therapies requiring large numbers of epidermal cells in the treatment of severe wounds, such as extensive burns.

Taken together, our results suggest that commitment to differentiation in vivo in neonatal skin is not an irreversible process and that the specific interactions of subpopulations of keratinocytes with their microenvironment leads to withdrawal from proliferation, detachment from the basement membrane, and progressive differentiation. Collectively, these data demonstrate that ex vivo manipulation of TA and differentiating cells results in their activation such that they demonstrate significant cell and tissue-regenerative capacity, despite the fact that they are destined to differentiate terminally if left unperturbed in vivo. We speculate that consistent with the spiral model of "stem-ness" proposed by Potten (46), whereby stem cell properties are lost gradually through successive rounds of division (as is the acquisition of irreversible commitment to differentiation), the more committed progeny of epidermal stem cells, including the early differentiating keratinocytes, retain proliferative potential that can be activated upon wounding, rather like the ability of mature lymphocytes to proliferate upon activation by appropriate stimuli. This feature of basal keratinocytes of the skin is entirely consistent with the overall physiological function of the epidermis to provide barrier function for the organism and most likely reflects unique compensatory mechanisms underlying cell renewal in the skin, such that damage to the stem cell population does not result in loss of epidermal tissue. These studies have strong implications for cellular therapies thought to require the targeting of epidermal stem cells for ex vivo expansion or gene therapy; clearly, circulating factors provided by the host are capable of promoting epidermal proliferation from all basal keratinocyte populations, removing the need for stem cell selection for clinical applications. In view of recent reports in the literature demonstrating the considerable plasticity exhibited by tissue-specific stem cells in their differentiation capacity when placed in the appropriate microenvironment in vivo, it may be possible to harness the vast proliferative potential of readily available and accessible keratinocyte progenitors of the skin for cellular therapies for other tissues $(47,48)$.

\section{Acknowledgments}

We thank Andrew Fryga and Ralph Rossi for their invaluable cell-sorting expertise. This work was supported by grants from Organogenesis Inc. and the National Health and Medical Research Council of Australia (981881) to P. Kaur. Amy Li is the recipient of an Australian Postgraduate Award. We thank Nancy Parenteau and Vincent Ronfard for valuable discussions.

1. Rheinwald, J.G., and Green, H. 1975. Serial cultivation of strains of human epidermal keratinocytes: the formation of keratinizing colonies from single cells. Cell. 6:331-343.

2. Billingham, R.E., and Reynolds, A.J. 1952. Transplantation studies of sheets of pure epidermal epithelium and of epidermal cell suspensions. Br. J. Plast. Surg. 5:25-36.

3. Billingham, R.E., and Silvers, W.K. 1968. Studies on the conservation of epidermal specificities of skin and certain mucosas in adult mammals. J. Exp. Med. 125:429-446.

4. Mackenzie, I.C., and Fusenig, N.E. 1983. Regeneration of organized epithelial structure. J. Invest. Dermatol. 81(1 Suppl.):189s-194s.

5. Gallico, G.G., 3rd, O’Connor, N.E., Compton, C.C., Kehinde, O., and Green, H. 1984. Permanent coverage of large burn wounds with autologous cultured human epithelium. N. Engl. J. Med. 311:448-451.

6. Compton, C.C., et al. 1989. Skin regenerated from cultured epithelial autografts on full-thickness burn wounds from 6 days to 5 years after grafting. A light, electron microscopic and immunohistochemical study. Lab. Invest. 60:600-612.

7. Mackenzie, J.C. 1969. Ordered structure of the stratum corneum of mammalian skin. Nature. 222:881-882.

8. Potten, C.S., and Bullock, J.C. 1983. Cell kinetic studies in the epidermis 
of the mouse. I. Changes in labeling index with time after tritiated thymidine administration. Experientia. 39:1125-1129.

9. Potten, C.S., Hume, W.J., and Parkinson, E.K. 1984. Migration and mitosis in the epidermis. Br. J. Dermatol. 111:695-699.

10. Morris, R.J., Fischer, S.M., and Slaga, T.J. 1985. Evidence that the centrally and peripherally located cells in the murine epidermal proliferative unit are two distinct cell populations. J. Invest. Dermatol. 84:277-281.

11. Mackenzie, I.C., and Bickenbach, J.R. 1985. Label-retaining keratinocytes and Langerhans cells in mouse epithelia. Cell Tissue Res. 242:551-556.

12. Potten, C.S. 1986. Cell cycles in cell hierarchies. Int. J. Radiat. Biol. 49:257-278.

13. Bickenbach, J.R., McCutecheon, J., and Mackenzie, I.C. 1986. Rate of loss of tritiated thymidine label in basal cells in mouse epithelial tissues. Cell Tissue Kinet. 19:325-333.

14. Kolodka, T.M., Garlick, J.A., and Taichman, L.B. 1998. Evidence for keratinocyte stem cells in vitro: long term engraftment and persistence of transgene expression from retrovirus-transduced keratinocytes. Proc. Natl. Acad. Sci. U. S. A. 95:4356-4361.

15. Pellegrini, G., et al. 1999. Location and clonal analysis of stem cells and their differentiated progeny in the human ocular surface. J. Cell Biol. 145:769-782.

16. Jones, P.H., Harper, S., and Watt, F.M. 1995. Stem cell patterning and fate in human epidermis. Cell. 80:83-93.

17. Jones, P.H., and Watt, F.M. 1993. Separation of human epidermal stem cells from transit amplifying cells on the basis of differences in integrin function and expression. Cell. 73:713-724.

18. Li, A., Simmons, P.J., and Kaur, P. 1998. Identification and isolation of candidate human keratinocyte stem cells based on cell surface phenotype. Proc. Natl. Acad. Sci. U. S. A. 95:3902-3907.

19. Kaur, P., and Li, A. 2000. Adhesive properties of human basal epidermal cells: an analysis of keratinocyte stem cells, transit amplifying cells, and postmitotic differentiating cells. J. Invest. Dermatol. 114:413-420.

20. Albert, M.R., Foster, R.A., and Vogel, J.C. 2001. Murine epidermal labelretaining cells isolated by flow cytometry do not express the stem cell markers CD34, Sca-1, or Flk-1. J. Invest. Dermatol. 117:943-948.

21. Bickenbach, J.R., and Chism, E. 1998. Selection and extended growth of murine epidermal stem cells in culture. Exp. Cell Res. 244:184-195.

22. Tani, H., Morris, R.J., and Kaur, P. 2000. Enrichment for murine keratinocyte stem cells based on cell surface phenotype. Proc. Natl. Acad. Sci. U. S. A. 97:10960-10965.

23. Potten, C.S. 1986. The cellular basis of skin injury after cytotoxic insult Br. J. Cancer. Suppl. 7:47-58.

24. Cotsarelis, G., Cheng, S.Z., Dong, G., Sun, T.T., and Lavker, R.M. 1989 Existence of slow-cycling limbal epithelial basal cells that can be preferentially stimulated to proliferate: implications on epithelial stem cells. Cell. 57:201-209.

25. Cotsarelis, G., Sun, T.T., and Lavker, R.M. 1990. Label-retaining cells reside in the bulge area of pilosebaceous unit: implications for follicular stem cells, hair cycle, and skin carcinogenesis. Cell. 61:1329-1337.

26. Lavker, R.M., and Sun, T.T. 2000. Epidermal stem cells: properties, markers, and location. Proc. Natl. Acad. Sci. U. S. A. 97:13473-13475.

27. Potten, C.S., and Booth, C. 2002. Keratinocyte stem cells: a commentary. J. Invest. Dermatol. 119:888-899.

28. Christophers, E. 1971. Cellular architecture of the stratum corneum. J. Invest. Dermatol. 56:165-169.

29. Allen, T.D., and Potten, C.S. 1974. Fine-structural identification and organization of the epidermal proliferative unit. J. Cell Sci. 15:291-319.
30. Lajtha, L.G. 1979. Stem cell concepts. Differentiation. 14:23-34

31. Asselineau, D., and Prunieras, M. 1984. Reconstruction of 'simplified' skin: control of fabrication. Br. J. Dermatol. 111(Suppl 27):219-222.

32. Bell, E., Ivarsson, B., and Merrill, C. 1979. Production of a tissue-like structure by contraction of collagen lattices by human fibroblasts of different proliferative potential in vitro. Proc. Natl. Acad. Sci. U. S. A. 76:1274-1278

33. Bell, E., et al. 1983. The reconstitution of living skin. J. Invest. Dermatol. 81(1 Suppl.):2s-10s

34. Kaur, P., et al. 1997. Identification of a cell surface protein with a role in stimulating human keratinocyte proliferation, expressed during development and carcinogenesis. J. Invest. Dermatol. 109:194-199.

35. Parenteau, N.L. 1994. Skin equivalents. In The keratinocyte handbook. I. Leigh and F.M. Watt, editors. Cambridge University Press. Cambridge, United Kingdom. 44-54.

36. Pouliot, N., Connolly, L.M., Moritz, R.L., Simpson, R.J., and Burgess, A.W. 2000. Colon cancer cells adhesion and spreading on autocrine laminin-10 is mediated by multiple integrin receptors and modulated by EGF receptor stimulation. Exp. Cell. Res. 261:360-371.

37. Parenteau, N.L., et al. 1991. Epidermis generated in vitro: practical considerations and applications. J. Cell Biochem. 45:245-251.

38. Weiss, R.A., Eichner, R., and Sun, T.T. 1984. Monoclonal antibody analysis of keratin expression in epidermal diseases: a 48- and 56-kdalton keratin as molecular markers for hyperproliferative keratinocytes. J. Cell Biol. 98:1397-1406.

39. Stoler, A., Kopan, R., Duvic, M., and Fuchs, E. 1988. Use of monospecific antisera and cRNA probes to localize the major changes in keratin expression during normal and abnormal epidermal differentiation. J. Cell. Biol. 107:427-446.

40. Mansbridge, J.N., and Knapp, A.M. 1987. Changes in keratinocyte mat uration during wound healing. J. Invest. Dermatol. 89:253-263.

41. Paladini, R.D., Takahashi, K., Bravo, N.S., and Coulombe, P.A. 1996. Onset of re-epithelialization after skin injury correlates with a reorganization of keratin filaments in wound edge keratinocytes: defining a potential role for keratin 16. J. Cell. Biol. 132:381-397.

42. Waseem, A., et al. 1999. Keratin 15 expression in stratified epithelia: downregulation in activated keratinocytes. J. Invest. Dermatol. 112:362-369

43. Pouliot, N., Saunders, N.A., and Kaur, P. 2002. Laminin 10/11: an alternative adhesive ligand for epidermal keratinocytes with a functional role in promoting proliferation and migration. Exp. Dermatol. 11:387-397.

44. Terzaghi, M., Nettesheim, P., and Williams, M.L. 1978. Repopulation of denuded tracheal grafts with normal, preneoplastic, and neoplastic epithelial cell populations. Cancer Res. 38:4546-4553.

45. Gilmour, S.K., Teti, K.A., Wu, K.Q., and Morris, R.J. 2001 A simple in vivo system for studying epithelialization, hair follicle formation, and invasion using primary epidermal cells from wild-type and transgenic ornithine decarboxylase-overexpressing mouse skin. J. Invest. Dermatol. 117:1674-1676.

46. Potten, C.S., and Loeffler, M. 1990. Stem cells: attributes, cycles, spirals, pitfalls and uncertainties. Lessons for and from the crypt. Development. 110:1001-1020.

47. Morrison, S. 2001. Stem cell potential: can anything make anything? Curr. Biol. 11:R7-R9.

48. Alison, M.R., et al. 2003. Plastic adult stem cells: will they graduate from the school of hard knocks? J. Cell Sci. 116:599-603. 